\title{
A 3D LEARNING GAME TO FOSTER COMPUTATIONAL THINKING IN K-12 EDUCATION
}

\author{
Myungjae Kwak, Middle Georgia State University, myungjae.kwak@mga.edu \\ Kirill M. Yurov, Missouri Western State University, kiryurov@gmail.com \\ Kevin S. Floyd, Middle Georgia State University, kevin.floyd@mga.edu
}

\begin{abstract}
Educational games hold a great promise for STEM education for K-12 students and need to be carefully designed to ensure that they are meeting educational objectives, providing immersive and entertaining experience. The paper outlines theoretical underpinnings for an engaging $3 D$ educational puzzle game for middle school students intended to both serve for educational purpose, which is teaching mathematics, computing concepts, and algorithmic thinking, and provide entertaining gameplay. To achieve the goal, we posit that the proposed game design will facilitate flow experience, in which people are fully immersed in an activity at hand. The design is also enhanced by an intelligent pedagogical agent, which student players will interact with and learn computational thinking from. Finally, the game also aims to create a positive attitude change about STEM and computing subjects, which middle school students, especially girls and minorities, perceive as a difficult subject, by fostering their self-efficacy in STEM subjects.
\end{abstract}

Keywords: Computational Thinking, Gaming Software, Collaborative Learning, Deeper Learning

\section{INTRODUCTION}

Computing has been considered a new literacy, which is defined as "the ability to carefully read and write a contemporary spoken language", and a vital skill to make use of digital technology for one's needs in the modern world [1]. An algorithm is typically defined as "a method to solve a problem that consists of exactly defined instructions" and algorithmic thinking, which is a core component of computing, is the ability to analyze a given problem, find sequences of instructions to solve the given problem, and improve the efficiency of an algorithm [2]. This research project envisions creating a futuristic, interactive 3D game-based virtual learning environment (VLE), in which students are completely engaged in learning challenging STEM and computing subjects, which are critical for success in the $21^{\text {st }}$ Century economy and changing society. The 3D game-based VLE will provide an immersive 3D educational puzzle game designed to engage K-12 students with algorithmic/ computational thinking [3, 2].

Despite the importance of computational thinking, discrete mathematics, computing, and algorithmic thinking remain under-prioritized in K-12 education. Moreover, computing education faces problems with diversity. According to a U.S. study on women in the workforce, $57 \%$ of professional occupations were held by women; however, only $26 \%$ of professional computing occupations are held by women [4], and only $5 \%$ of the science and engineering occupations are held by African-Americans [5]. In a south-eastern region of United States, where this research project is being conducted, the population consists of 53\% female, 53\% African-American; and 25\% of the population fall below the poverty line. Females, African-Americans, and the poor - both urban and rural - are demographics traditionally underrepresented in STEM and computing subjects. We believe that a proposed 3D educational puzzle game, an engaging game designed around the theme of computational algorithms, is a tool to foster appreciation for and interest in a broad array of STEM subjects in the region.

The project team, which has closely work with the school district of the region, will be able to bring together middle and high school students, teachers, undergraduates, graduates, and higher education faculty in a series of formal and informal information sessions to launch this project initiative. This will have the pragmatic effect that the project team can receive direct feedback from the program's users, thereby gaining valuable insights and inspiration. These information and feedback sessions will also reach the student players at an emotional level, inspiring them to stay in school and select STEM classes in high school and, potentially, continue to post-secondary education in a STEM program of study. The quantitative analysis of the learning outcomes will be captured from the game server, helping teachers identify areas where their students need more assistance and will enable the project leaders to evaluate and modify the learning targets. 
Research shows that girls tend to pull away from STEM subjects - including computing disciplines - around middle school, while rates of boys in these classes stay steady. There is evidence that girls exposed to very basic programming concepts early in life are more likely to major in computing fields in college. That's why approaches like Time Travelers' Adventure, steeped in research on how to get and keep girls and other underrepresented minorities in computer science class, have great potential [6]. The Bureau of Labor Statistics projects that computer and mathematical occupations are expected to increase during 2012-2022 by $18 \%$. More than half of available job openings will occur in the information technology cluster, including programming and software development areas. This change requires that the nation's youth obtain specific skills and be provided opportunities to understand how they can best be prepared for the changes in workforce skill requirements. Lack of STEM-related skills will negatively impact women and minorities' chances to compete for employment, wages, and leadership in all professional fields [7]. Time Travelers' Adventure is specifically designed for a game for girls and minorities, but since our game has many game scenes, we will be able to adopt and evaluate gender-inclusive game design principles [8,9] and various design features for minorities [10], including African-Americans, in some of the scenes.

What makes the proposed game unique is that flow concept, which was put forward by a positive psychologist, Mihaly Csikszentmihalyi $[11,12]$. Intelligent game agents/tutors $[13,14,15]$ will be integrated into the learning software so that students can more effectively learn while being fully engaged and interacting with game agents. Flow is the mental state of operation in which people fully immerse themselves in an activity and feel energized focus and enjoy the activity $[12,16]$. The proposed educational game will be designed to facilitate flow experience, engagement, interaction, collaboration, and deeper learning in the classroom and informal settings.

Thus, our proposed game will provide students with positive reinforcement and measurable goals that come from a stimulus-response interface. Using the computer program provides players/students with individualized instruction, motivation, student engagement, self-paced learning and self-regulation. The design and nature of this project is to foster individualized instruction, facilitate student freedom to maneuver around to engage in game tasks and challenges, minimize or eliminate boredom, and increase rigor for high-achieving students. These goals will be primarily pursued in the first phase of this research project which focuses on the game design. By collecting student feedback via the pilot study, we would be able to enhance our learning game (the second phase of this research project). Finally, processing collected data concerning the effectiveness of the proposed game would support analytical inferences that are both research- and practice-oriented (the third phase of the research project). Since our game will be deployed on a public game server, researchers from different disciplines including psychology, education, and computer science, will be able to conduct various game analytics [17] by using players' behavioral data provided by our game server.

\section{PRIOR RESEARCH}

A number of studies have been conducted to determine the benefits of using games for informal learning and transforming education $[18,19,20,21,22]$. Educational game researchers typically implement their games to encourage problem-based, experiential, engaged, and situational learning and support deep learning by providing immediate feedback, personalization, and challenge $[20,23,22,24]$. While a number of researches show the positive effects of educational games [25, 26, 27, 28, 29], some studies report neutral or little effect $[29,30,31,32$, 33]. Therefore, we believe that much more study and research need to be done for effective design, implementation, and usage of educational games.

Our proposed work will provide a contribution to this promising, but partially established field, by incorporating immersive $3 D$ virtual worlds and intelligent pedagogical agents with educational games and evaluating its effectiveness using experimental design. 3D features [34,35] and intelligent pedagogical agents $[16,36]$ have been successfully used in a number of educational or learning games. However, most of them were 2D casual games or implemented for different contexts and we found no game was developed as an immersive 3D adventure game with intelligent agents and designed for the computing discipline. 


\section{RESEARCH METHODOLOGY}

\section{Research Question and Research Model}

The first phase of our project focuses on the design and development of the 3D adventure puzzle game, in which players travel across different time periods using a time machine and solve a series of puzzles by programming the movements of robots and collecting various game objects. The following research question will be investigated early in the project.

Question 1 (Design Research): What is an effective design for a 3D educational puzzle game that aims to teach challenging mathematics and computing concepts and foster algorithmic thinking in middle school students?

The second phase consists of the pilot study and consequent enhancement of the initial game design and the development of the game server platform. The third phase is devoted to the evaluation of the enhanced game design by analyzing player data collected from game server to find out whether or not and to what extent our game is effective in fostering computational thinking and changing students' attitudes towards computing discipline. The following research question will be investigated in the phases focusing on game enhancement and data analytics.

Question 2 (Empirical Research): To what extent is a 3D puzzle game aimed at middle school students more effective in teaching computing concepts and algorithmic thinking than a simple 2D casual puzzle game?

We hypothesize that a 3D adventure puzzle game designed for a flow experience and interaction with intelligent agents is more effective since a flow game experience may positively affect deeper learning and interactive gaming activities and stimulate both deeper learning and collaborative learning.

Figure 1 shows the model of our proposed study including constructs, types of learning, and learning outcomes. Based on the model, we defined six hypotheses that we will investigate as part of answering Question 2.

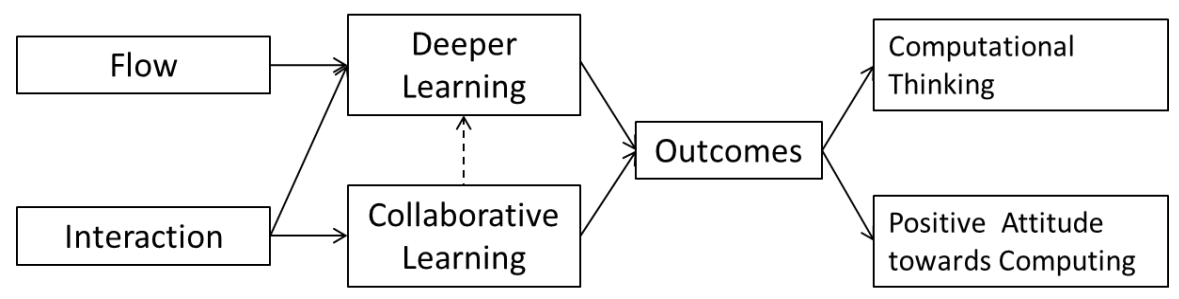

Figure 1. Model of the Proposed Study

\section{Flow and Deeper Learning Hypotheses}

Csikszentmihalyi [12] defines flow as a mental state of complete absorption in what a person does [37, 38]. In the flow state, a person is completely focused and motivated and enjoys the activity [38]. Moreover, emotions are not just contained and channeled, but positive, energized, and aligned with the task at hand [37, 12]. According to Csikszentmihalyi, people experience flow several cognitive components are present: (1) clear goals that, while challenging, are still attainable, (2) strong concentration and focused attention, (3) intrinsically rewarding activity, (4) feelings of serenity, (5) timelessness, (6) immediate feedback, (7) knowing that the task is doable, (8) feelings of personal control over the situation and the outcome, (9) lack of awareness of physical needs, and (10) complete focus on the activity itself [12,39]. In learning contexts, students are optimally engaged when the level of challenge is a good match for their skills and perceived challenges and skills are both high and in balance and when this optimal learning environment are realized, students are fully immersed in the activity and the learning outcome is maximized [40].

The William and Flora Hewlett Foundation [41, 42] defines deeper learning as "a set of competencies students must master in order to develop a deep understanding of academic content and apply their knowledge to problems in the classroom and on the job" [43]. It is a combination of (1) a deeper understanding of core academic content, (2) the ability to apply that understanding to novel problems and situations, and (3) the development of a range of 
competencies, including soft skills and self-control [43]. Through deeper learning, students learn how to think critically, collaborate, communicate effectively, direct their own learning, and obtain an academic mindset [42]. We believe that the combination of immersive 3D virtual worlds, a series of challenging puzzles, and illustrative 3D characters of famous scientists and mathematicians, which will be implemented in Time Travelers' Adventure, is likely to facilitate flow experience $[37,44]$ and thus students are fully absorbed in solving puzzles to have a deeper understanding of computational mathematics and learn how to apply the understanding to new situations.

Hypothesis 1: The higher the degree of deeper learning, the higher the effects on computational thinking (Hypothesis 1.1) and positive attitude toward computing subjects (Hypothesis 1.2).

Hypothesis 2: Flow experience has a more positive effect on deeper learning than no flow experience.

\section{Interaction, Deeper Learning, and Collaborative Learning Hypotheses}

Interactions with others can be such a powerful learning tool since real depth of understanding happens when the learner can express the new learning themselves, either through discussions (interactions) or writing [45, 46]. In the proposed game, there can be two types of interactions; interactions with artificial intelligent agents, which are avatars of famous scientists and mathematicians, and interactions with other game players either in game or outside game. People might think that interactions with other players inside or outside the game may have adverse effects since players can simply let others know the answers to the puzzles. However, in the proposed game, puzzles in each scene are randomly generated based on content generation algorithms [47, 48] and players will face different puzzles. Therefore, players cannot help others by simply sharing their answers, but they will be able to help others only if they completely understand mathematical concepts and the logic behind puzzles. This type of interaction leads to deeper learning [41, 42].

Collaborative learning [49] occurs when two or more people learn or attempt to learn something together by using one another's knowledge or resources [50]. Gokhale [40] asserts that collaborative learning enhances critical thinking since the active exchange of ideas within small groups not only increases interests, but also promotes critical thinking and students are capable of performing at higher intellectual levels when asked to work in collaborative situations than when asked to work individually [51]. Therefore, we believe that in the game interactions with both intelligent agents and other players will facilitate collaborative learning, in which the active exchange of knowledge can enhance computational thinking and increased interests among students will lead to their attitude change toward computing discipline.

Hypothesis 3: The higher the collaborative learning, the higher the effects on computational thinking (Hypothesis 3.1) and a positive attitude toward computing subjects (Hypothesis 3.2).

Hypothesis 4: Interaction has a more positive effect on deeper learning than no interaction.

Hypothesis 5: Interaction has a more positive effect on collaborative learning than no interaction.

Hypothesis 6: Interaction has a more positive effect on deeper learning in a collaborative setting than in an individual one.

\section{IMPLEMENTATION PLAN AND CONCLUSIONS}

\section{Project Objectives}

In this project, the game will be developed iteratively with inputs from our target audiences, science and math teachers at middle and high schools, undergraduate and college students, higher education math and science faculty, and game design and development experts.

The game has the following intended learning outcomes:

1. Students should be able to demonstrate computational thinking in the context of the mathematics and computing concepts taught in the game including Euler path, Cartesian plane, linear equations, pattern recognition and vector arithmetic. 
2. Students should develop a positive attitude towards computing subjects and show more interest in exploring and pursuing professional computing occupations.

The first objective, on computational thinking, is to help envision a future in which people acquire the modern day computing skills to not only use but also understand and create the computer program for real-world problem solving. By learning the necessary skills in an engaging, collaborative manner, we expect that students' selfconfidence on learning underlying mathematics and computation concepts would increase, and this would make them more motivated in engaging in computational techniques and practices. The second objective, on positive attitude towards computing, is to help students identify what computational techniques could mean in their lives. We expect that a positive attitude change would make students more interested in pursuing computational occupations [52]. We believe that both objectives will help address the problem of underrepresentation of women and minorities in computing.

\section{Game Development}

We envision a 3D virtual adventure puzzle game in which students can learn underlying computing concepts and algorithmic thinking while enjoying game challenges and interacting with intelligent agents and collaborating with other players in an informal setting. We chose a 3D adventure puzzle game because the 3D adventure game genre tends to be both immersive and non-violent; and, puzzle games are appropriate to teach complicated algorithmic thinking. Technically, we plan to use Unity 5 [53] as the main development tool since it allows us to design and build fascinating, immersive 3D virtual worlds relatively easily and take advantage of various game development assets, such as a physics engine, a dialogue system, myriad 3D models, and assorted textures and materials, made by Unity Technologies and their community. In addition, Unity allows us to publish our game to various gaming platforms including PC, Mac, Smartphones, tablet, game consoles, et al, which means we do not need to develop different versions of this game for other platforms.

In the game, players first learn basic mathematics and computing concepts from intelligent agents, which will be created as 3D avatars of famous scientists and mathematicians. Then the players are presented with procedurally generated puzzle problems, thematically linked to the very scientists and mathematicians, and solve them by programming a robot/spaceship or manipulating various game objects. As they progress through the game, they learn more about how computer programming works and solve the broad array of challenging puzzles for which algorithms can be used. At the same time, interacting with famous people from history helps players learn about the history of computing and applied math, as well as identify with role models. Finally, as they make progress through the game, players can customize their avatar and their robot to personalize and engage with the game.

When the game starts, players find themselves lost in time and an angel appears and informs them that players can go back home after completing a series of missions. Then the angel gives a brief tutorial about how to complete each mission. After completing the tutorial, players are guided to the first mission of the game. The "angel" gives hints or guides when players are stuck. The game map presents time and space as a two-dimensional surface, and players can click on different sections to visit when and where one of the historical characters lived - ancient Egypt, Victorian England, pre-independence India, AD 2100, etc. Missions/problems are designed to have different levels of difficulty and students will not be allowed access to different areas of the map until they have acquired knowledge in required subjects.

The project team reviewed state's Common Core Math Standards for middle and high schools and extracted a list of topics related to computing, mathematics, computational thinking, and science. The following scenes are depict the mathematics, computing concepts, and algorithmic thinking linked to famous scientists and mathematicians which are featured in each mission in the game.

Leonhard Euler: The player will send a robot into a vortex of a hazardous area where it will gather various machine parts at specified locations then exit the vortex before it closes. The object is to calculate the shortest Euler cycle to visit all stops in the shortest time possible. The time limit could vary with difficulty level. This game scene incorporates algorithms and discrete mathematics (Figure 2). 


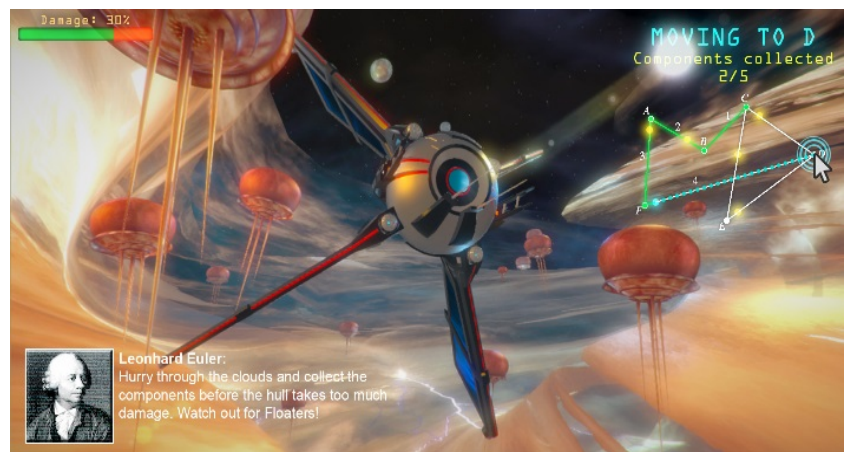

Figure 2. Example Game Scene for Eulerian Cycle Puzzle

Grace Hopper: The player will shoot the moths on a Cartesian plane that threaten to short circuit the robot. Moths will be located at a certain position on the plane. The player must pick the correct linear equation that will target the moth. This game scene incorporates linear equations, slope and y-intercept (Figure 3).

Carl Friedrich Gauss: The player could be riding on a vehicle following a straight path and must intercept a train or other vehicle on a straight path to collect a machine part. The player would use two linear equations that the player must solve simultaneously so that they intercept the train. To increase the skill level quadratic equations could be used. This game scene teaches how to solve equations (Figure 4).

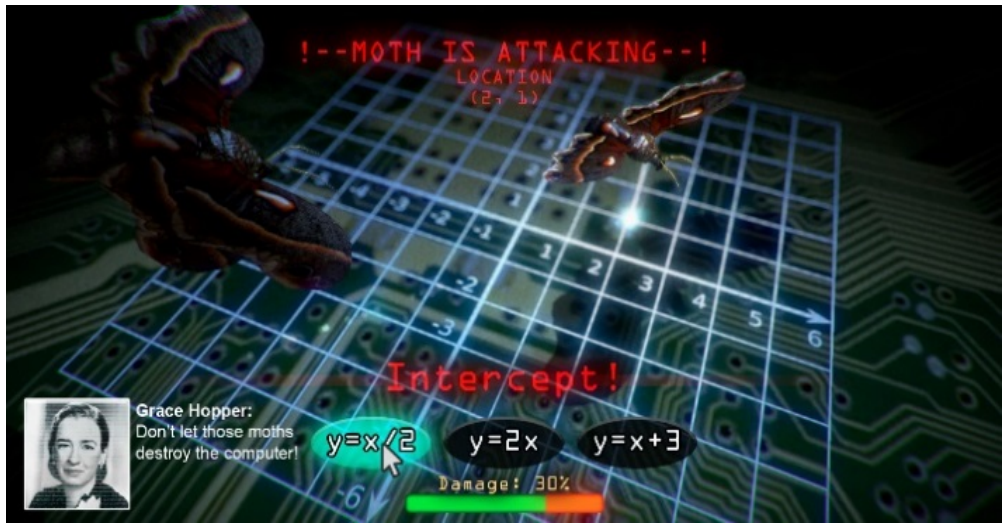

Figure 3. Example Game Scene for Cartesian Plane Puzzle

Srinivasa Ramanujan: The player will guide the robot through traffic to find a machine part at a final destination. The player will program the route by recognizing patterns in the street numbers. More difficult patterns can be used for different skill levels. This game scene incorporates pattern recognition and arithmetic operations.

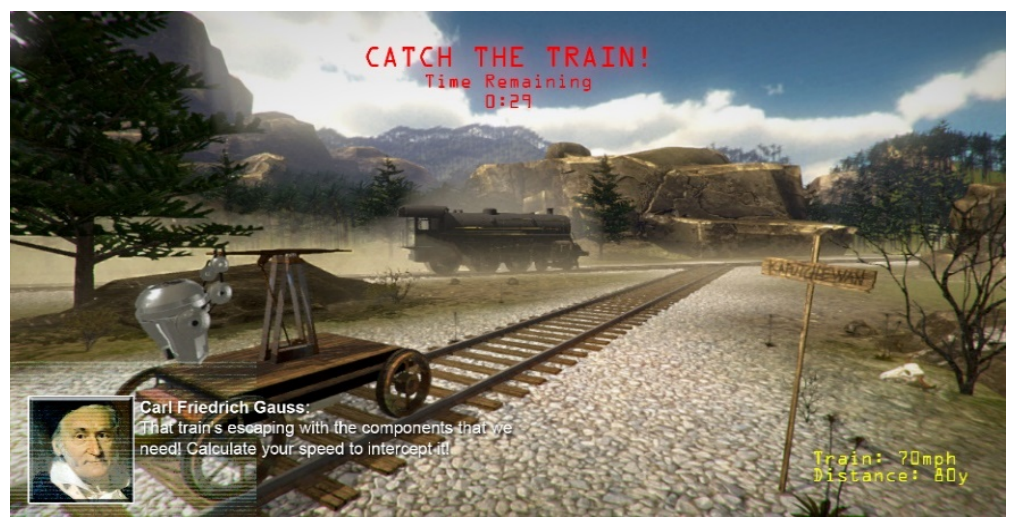

Figure 4. Example Scene for Quadratic Equation Puzzle 
Isaac Newton: The player will guide Isaac Newton as he pushes an apple tree through a maze. Once he has reached the end of the maze he can plant the tree and receive a machine part. The player must use vectors to determine the path of Isaac Newton. This game scene incorporates vectors and vector arithmetic. The above are only five of the extracted topics and we plan to implements a total of 10 scenes in this project.

\section{Evaluation}

To achieve proposed learning outcomes, we will develop our game using an iterative agile development methodology with two types of evaluations: a formative evaluation and a summative evaluation [54]. The purpose of formative assessment is "to monitor student learning to provide ongoing feedback [54]," which will be iteratively used by the project team to improve the design of the proposed game. This formative assessment will be used to answer the first research question of this study. We will use this qualitative method to systematically analyze outcomes of test sessions and outline recommendations for the next iteration.

The summative evaluation combines quantitative and qualitative analysis methods. It will be used to assess the learning outcomes of the game by answering the second research question of the study. To answer the question, we defined six hypotheses based on our research model (see Figure 1). To test our hypotheses, we will conduct an independent factor analysis [18] with 3x2 factorial design. The independent variables (IVs) consists of Game Type (2D simple puzzle game, 3D adventure puzzle game with no intelligent agents, and 3D adventure game with intelligent agents) and Game Mode (single player and multiple players). This factorial design will allow us to analyze the effects of both 3D graphics and intelligent agents. Participants will be randomly assigned to one of six conditions.

Participants will play one of three versions of our proposed puzzle game: 2D and 3D versions without AI agents and collaborative features or the $3 \mathrm{D}$ version with $\mathrm{AI}$ agents and collaborative features. The exact gameplay time will be determined based on test sessions. Before and after playing, participants will take a form of the pre- and postquestionnaire and test. We will deploy games on the game server platform and integrate the questionnaire materials into the games, therefore ensuring that the participants do not feel like they are part of an experiment but rather participate in a fun and enjoyable activity. The pre-questionnaire will measure the background variables: basic demographics and game attitudes. For measuring game attitude, we will incorporate the New Computer Game Attitude Scale (CGAS) [19], a validated survey based on the original Computer Game Attitude Scale [20], which was developed to evaluate middle school students' attitudes toward educational computer games. The instrument measures students' opinions, feelings, and specific behaviors regarding the use of computer games.

The post-questionnaire will measure the following outcome variables: flow experience, deeper learning and game experience. To measure flow experience, we plan to use the Experience Sampling Method (ESM) proposed by Csikszentmihalyi [21, 22]. Rubrics for evaluating deeper learning will be developed by referring guidelines published by SCOPE: Stanford Center for Opportunity Policy in Education [23] and Rand Corporation [24]. Game experience involves students' opinions on playing Time Travelers' Adventure. We intend to use the Game Experience Questionnaire (GEQ) [37, 25], which aims to capture the full spectrum of digital game experiences. The comprehensive pre- and post-test will address students' algorithmic/computational thinking. Previous studies on algorithmic thinking that included objective tests showed the effectiveness of measuring change in students' knowledge with software design scenarios [26]. Design scenarios present individual students with a short description of a realistic design challenge and then ask them to describe how they would solve the problem [27, 28, 55, 29, 30, 31]. The tests are written with multiple choice (MC) questions, using guidelines for creating effective MC questions $[32,33]$, and the content is examined by experts in computing discipline.

This research project will conduct two prototype tests and a full study along with formative and summative evaluations to identify an effective design of a 3D educational puzzle game aimed at fostering computational thinking. The two pilot tests and a full study will show whether a combination of an immersive 3D game world and interactive intelligent pedagogical agents indeed increase deeper learning and collaborative learning and thus computational thinking. Based on the test results, a 3D adventure puzzle game will be developed and deployed in a public game server. Along with pilot tests and full study results, player data that can be collected from the game server will allow the project team and other researchers to conduct various game analytics. 


\section{CONCLUSIONS}

STEM subjects including computation techniques are vital to the modern economy and society, yet women and minorities, have been underrepresented in STEM fields. This research project proposal is designed to achieve an early exposure to algorithmic thinking and computing through an innovative and engaging way. In the game, by travelling through time to meet famous scientists and mathematicians, students can learn about computational thinking while enjoying gameplay and customizing their avatars as a reward for successful problem solving, which is the same psychological tool exploited by famous games like FarmVille.

\section{REFERENCES}

1. M. Prensky, "Programming is the new literacy," Edutopia magazine, 2008.

2. G. Futschek, "Algorithmic thinking: the key for understanding computer science," in Informatics education-the bridge between using and understanding computers, Springer Berlin Heidelberg, 2006, pp. 159-168.

3. S. Cooper, W. Dann and R. Pausch, "Developing algorithmic thinking with Alice," in The Proceedings of ISECON 2000, 2000.

4. National Center for Women Information Technology, "Women and Information Technology by the Numbers," 2014. [Online]. Available: https://www.ncwit.org/sites/default/files/resources/btn_02282014web.pdf.

5. National Science Foundation, "Women, Minorities, and Persons with Disabilities in Science and Engineering 2015," 2015. [Online]. Available: http://www.nsf.gov/statistics/2015/nsf15311/digest/nsf15311-digest.pdf.

6. K. Hayden, Y. Ouyang, L. Scinski, B. Olszewski and T. Bielefeldt, "Increasing student interest and attitudes in STEM: Professional development and activities to engage and inspire learners," Contemporary Issues in Technology and Teacher Education, vol. 11, no. 1, 2011.

7. J. Oakes, Lost Talent: The Underparticipation of Women, Minorities, and Disabled Persons in Science, Rand Corp., Santa Monica, CA., 1990.

8. S. G. Ray, Gender inclusive game design, Charles River Media, 2004.

9. M. D. Dickey, "Girl gamers: the controversy of girl games and the relevance of female - oriented game design for instructional design," British journal of educational technology, vol. 37, no. 5, pp. 785-793, 2006.

10. T. Barnes, H. Richter, E. Powell, A. Chaffin and A. Godwin, "Game2Learn: building CS1 learning games for retention," ACM SIGCSE Bulletin, vol. 39, no. 3, pp. 121-125, 2007.

11. M. Csikszentmihalyi, Flow, Springer Netherlands, 2014.

12. M. Csikszentmihalyi, Flow and the Psychology of Discovery and Invention, New York: HarperPerennial, 1997.

13. M. W. Easterday, V. Aleven and R. Scheines, "Using tutors to improve educational games," in Artificial Intelligence in Education, Springer Berlin Heidelberg, 2011, pp. 63-71.

14. V. M. Holland, M. R. Sams and J. D. Kaplan, Eds., Intelligent language tutors: Theory shaping technology, New York: Routledge, 2013.

15. M. El-Nasr, A. Drachen and A. Canossa, Game Analytics: Maximizing the Value of Player Data, Springer, 2013.

16. C. Conati and M. Klawe, "Socially intelligent agents in educational games," in Socially Intelligent Agents, Springer, 2002, pp. 213-220.

17. W. Admiraal, J. Huizenga, S. Akkerman and G. t. Dam, "The concept of flow in collaborative game-based learning," Computers in Human Behavior, vol. 27, pp. 1185-1194, 2011.

18. H. Attias, "Independent Factor Analysis," Neural Computation, vol. 11, pp. 803-851, 1999.

19. E. Z. F. Liu, C. Y. Lee and H. J. Chen, "Developing a New Computer Game Attitude Scale for Taiwanese Early Adolescents," Educational Technology \& Society, vol. 16, no. 1, pp. 183-193, 2013.

20. K. K. Chappell and C. S. Taylor, "Evidence for the reliability and factorial validity of the computer game attitude scale," Journal of Educational Computing Research, vol. 17, no. 1, pp. 67-77, 1997.

21. J. Nakamura and M. Csikszentmihalyi, "The concept of flow," in Handbook of positive psychology, 2002, pp. $89-105$.

22. G. Moneta, "On the measurement and conceptualization of flow," in Advances in flow research, Springer New York, 2012, pp. 23-50.

23. L. Darling-Hammond and F. Adamson, "Developing Assessments of Deeper Learning: The Costs and Benefits of Using Tests that Help Students Learn," Stanford Center for Opportunity Policy in Education, 2013.

24. K. Yuan and V.-N. Le, "Measuring Deeper Learning Through Cognitively Demanding Test Items - Results from the Analysis of Six National and International Exams," RAND Corporation, 2014. 
25. K. Poels, W. Ijsselsteijn and Y. de Kort, "Procedural Content Generation Questionnaire," in Proceedings of Meaningful Play 2008, 2008.

26. K. Brennan and M. Resnick, "New frameworks for studying and assessing the development," in Proceedings of the 2012 annual meeting of the American, Vancouver, Canada, 2012.

27. G. Bear, H. Richards and P. Lancaster, "Attitudes toward computers: Validation of a computer attitudes scale," Journal of Educational Computing Research, vol. 3, no. 2, pp. 207-218, 1987.

28. B. Ericson and T. McKlin, "Effective and sustainable computing summer camps," in Proceedings of the 43rd ACM technical symposium on Computer Science Education, 2012.

29. Munson, B. Moskal, A. Harriger, T. Lauriski-Karriker and D. Heersink, "Computing at the high school level: Changing what teachers and students know and believe," Computers \& Education, vol. 57, no. 2, pp. 1836$1849,2011$.

30. J. M. Walker, D. S. Cordray, P. H. King and S. P. Brophy, "Design scenarios as an assessment of adaptive expertise," situations, vol. 1, no. 2, 2006.

31. L. Werner, J. Denner, S. Campe and D. Kawamoto, "The fairy performance assessment: measuring computational thinking in middle school," in Proceedings of the 43rd ACM technical symposium on Computer Science Education, 2012.

32. R. B. Frary, "More multiple-choice item writing do's and don'ts," Practical Assessment, Research \& Evaluation, vol. 4, no. 11, 1995.

33. J. Kehoe, "Writing multiple-choice test items.," Practical Assessment, Research \& Evaluation, vol. 4, no. 9, 1995.

34. C. S. González and F. Blanco., "Integrating an educational 3D game in Moodle," Simulation \& Gaming, 2008.

35. D. Coyle, M. Matthews, J. Sharry, A. Nisbet and G. Doherty, "Personal Investigator: A therapeutic 3D game for adolecscent psychotherapy," Interactive technology and smart education, vol. 2, no. 2, pp. 73-88, 2005.

36. Thomaz and C. Breazeal, "Teachable robots: Understanding human teaching behavior to build more effective robot learners," Artificial Intelligence, vol. 172, no. 6-7, pp. 716-737, 2008.

37. M. Hendrikx, S. Meijer, J. Van Der Velden and A. Iosup, "Procedural content generation for games: A survey," ACM Transactions on Multimedia Computing, Communications, and Applications (TOMCCAP), vol. 9, no. 1, 2013.

38. K. Bruffee, Collaborative Learning, Baltimore: The Johns Hopkins University Press, 1993.

39. P. Dillenbourg, "Collaborative Learning: Cognitive and Computational Approaches," in Advances in Learning and Instruction Series, New York, NY, Elsevier Science, 1999.

40. A. Gokhale, "Collaborative Learning Enhances Critical Thinking," Journal of Technology Education, vol. 7, no. $1,1995$.

41. L. Vygotsky, Mind in society: The development of higher psychological processes, Cambridge: Harvard University Press, 1978.

42. C. Aldrich, The Complete Guide to Simulations and Serious Games: How the Most Valuable Content Will be Created in the Age Beyond Gutenberg to Google, Pfeiffer, 2009.

43. S. Egenfeldt-Nielsen, Beyond Edutainment: The Educational Potential of Computer Games, Continuum Press, London, UK, 2007.

44. J. Gee, What Video Games Have To Teach Us about Learning and Literacy, Palgrave Macmillan, New York, NY, 2003.

45. D. Shaffer, How computer games help children learn, Palgrave Macmillan, New York, NY, 2006.

46. K. Squire, Video games and learning: Teaching and participatory culture in the digital age, Teachers College Press, New York, NY, 2011.

47. S. De Freitas and P. Maharg, Digital Games and Learning, Continuum Press, London, UK, 2011.

48. J. Gee, Good games and good learning, Peter Lang Publishing, New York, NY, 2007.

49. S. Barab, M. Thomas, T. Dodge, R. Carteaux and H. Tuzun, "Making learning fun: Quest Atlantis, a game without guns," Educational Technology Research and Development, vol. 53, no. 1, pp. 86-107, 2005.

50. D. Clark, B. Nelson, H. Chang, C. D'Angelo, K. Slack and M. Martinez-Garza, "Exploring Newtonian mechanics in a conceptually-integrated digital game: Comparison of learning and affective outcomes for students in Taiwan and the United States," Computers and Education, vol. 57, no. 3, p. 2178-2195, 2011.

51. F. Ke and B. Grabowski, "Gameplaying for maths learning: Cooperative or not?," British Journal of Educational Technology, vol. 38, no. 2, p. 249-259, 2007. 


\section{Issues in Information Systems}

Volume 16, Issue III, pp. 20-29, 2015

52. K. Pugh, L. Linnenbrink-Garcia, K. Koskey, V. Stewart and C. Manzey, "Motivation, learning, and transformative experience: A study of deep engagement in science," Science Education, vol. 94, no. 1, pp. 1-28, 2010.

53. "Unity," Unity, 2015. [Online]. Available: http://unity3d.com/.

54. W. Harlen and M. James, "Assessment and learning: differences and relationships between formative and summative assessment," Assessment in Education, vol. 4, no. 3, pp. 365-379, 1997.

55. D. Heersink and B. Moskal, "Measuring high school students' attitudes toward computing," in Proceedings of the 41st ACM technical symposium on Computer science education, 2010.

56. "Census.gov," United States Census Bureau, 2015. [Online]. Available: http://www.census.gov/.

57. "Georgia Science Standards," Georgia Department of Education, 2015. [Online]. Available: https://www.georgiastandards.org.

58. "Mathematics Standards," Common Core State Standards Initiative, [Online]. Available: http://www.corestandards.org/Math/. [Accessed 2015]. 